\title{
To Evaluate and Compare the Efficacy of Propofol, Etomidate as Induction Agent in Maintaining Haemodynamic Stability in Elective Surgery Under General Anaesthesia
}

\author{
${ }^{1}$, Mr.Syed Raashid Andrabi, ${ }^{2}$ Dr.Ajay Vikram Singh \\ National institute of medical science and Research, Jaipur Rajasthan, 303121 \\ Nims hospital, Jaipur Rajasthan, 303121 \\ DOI: 10.29322/IJSRP.10.03.2020.p9906 \\ http://dx.doi.org/10.29322/IJSRP.10.03.2020.p9906
}

\begin{abstract}
Hemodynamic stability at the time of induction of anaesthesia and during surgery has been major concern for the anaesthetist of both ancient and modern era's .Induction agent's causes vasodilatation, myoclonic seizures, nausea and vomiting and attenuation of axis thereby decreasing blood pressure. The aim and objective of this study is to evaluate the hemodynamic effect of etomidate and propofol and as induction agents in elective surgeries under general anaesthesia.
\end{abstract}

To observe any postoperative adverse effects such

To observe any postoperative adverse effects such as nausea, vomiting or seizures with propofol and etomidate as induction agent.

\section{INTRODUCTION}

Hemodynamic stability at the time of induction of anaesthesia and during surgery has been a major concern for the anaesthetist of both Ancient and modern eras. The maintenance of hemodynamic stability during induction of anaesthesia is dependent on both basal tone of the autonomic nervous system and also importantly influenced by baroreceptor reflex regulation of autonomic outflow influencing cardiac function and peripheral vascular resistance. ${ }^{(1)}$

Direct laryngoscopy and intubation produces marked circulatory effects known as pressor response, characterised by a sudden increase in heart rate and altered rhythm. Pressor response to laryngoscopy and intubation is documented fact in patients, under a variety of anaesthetic techniques. ${ }^{(2-3)}$

The effects of laryngoscopes and intubation on the cardiovascular system were noted early that the cardiac reflex could originate in the trachea, larynx and bronchi. These reflexes were named vasovagal since both the afferent and efferent paths of the reflex were assumed to the vagus nerve, however In 1990 concluded that these changes could be attributed to the stimulation of cardio accelerator nerves implying an increase in the cardiac sympathetic tone rather than vagal stimulation. This response is due to an increase in cardiac output rather than an increase in systemic vascular resistance. ${ }^{(4)}$

It is proposed that the mechanism of hemodynamic and catecholamine response to or tracheal intubation is that of somato-visceral reflex. Direct laryngoscopy activates proprioceptors at the base of the tongue which leads to hypertension, tachycardia and other 


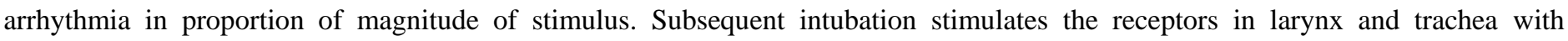
enhancement of hemodynamic and epinephrine response. ${ }^{(5)}$

The mean increase in arterial pressure due to laryngoscopy and intubation may be upto $20-25 \mathrm{mmHg}$. This peak response occurs approximately 30-35 sec after laryngoscopy. These cardiovascular changes due to direct laryngoscopy and intubation are transient, variable and unpredictable and usually well tolerated by healthy individuals, however these changes may be fatal in patients with hypertension, coronary artery disease or raised intracranial tensions.

It was also demonstrated that there is an increase in concentration of catecholamines like adrenaline and non adrenaline in response to the stimulus of laryngoscopy and intubation ${ }^{(6)}$

Wide range of intravenous induction agents of anaesthesia is now available. Thiopentone, propofol, etomidate, ketamine are used for induction to lower the stress response to laryngoscopy and intubation and to maintain better hemodynamic stability at the time of induction and during surgery.

Induction agents cause vasodilatation, myoclonic seizures, nausea, vomiting and attenuation of Autonomic Nervous System thereby decreasing blood pressure. Each intravenous anaesthetic induction agent affects hemodynamic changes differently. Thiopental is a commonly used induction agent.

In this study, we aim to evaluate the hemodynamic effects of propofol and etomidate in order to find the better hemodynamic stability during induction, laryngoscopy, intubation and during surgery under general anaesthesia in elective surgeries.

\section{MATERIAL AND METHODS}

This randomized double blind clinical study was conducted in the department of anaesthesia National institute of medical sciences Rajasthan jaipur, after approval from Institutional Ethical Committee ,on 60 patients aged between 18 to 60 years of either sex , ASA physical status I and II undergoing elective surgery lasting for approximately 2 hrs under general anaesthesia. Written informed consent was taken from all patients. The patients were randomly divided into three groups. Randomization was done by computer generated random numbers tables.

Group I induction with inj.propofol (2mg/kg IV)

Group II induction with inj.etomidate $(0.3 \mathrm{mg} / \mathrm{kg}$ IV)

Patient having following criteria were excluded from the study

1) Cardiac, hepatic and renal disease

2) Respiratory diseases

3) Known hypertensive

4) Known diabetic

5) Epilepsy

6) Pregnant patients

7) Known case of difficult airway (MP grade III and IV)

Baseline heart rate (preoperative) systolic blood pressure (SBP) diastolic blood pressure (DBP) mean blood pressure (MBP) and oxygen saturation (SPO2) and end tidal carbon dioxide (ETCO2) were noted.

The patients were kept nil per oral for 8 hours prior to the surgery. All patients were premedicated with tab.alprazolam $0.25 \mathrm{mg}$; tab Ranitidine $150 \mathrm{mg}$ at night before surgery and in the morning. All patients received inj.glycopyrolate $0.2 \mathrm{mg}$ i.v.In preoperative ward prior to the surgery. On arrival at operation theatre standard anaesthesia monitors including pulse oxymetry, electrocardiogram, non invasive blood pressure (NIBP) was attached and hemodynamic parameters were recorded. A $18 \mathrm{G}$ intravenous cannula was secured and ringer lactate infusion was started. Inj midazolam $0.025 \mathrm{mg} / \mathrm{kg}$ iv and inj. Nalbuphine $0.1 \mathrm{mg} / \mathrm{kg}$ was given 2 minutes before http://dx.doi.org/10.29322/IJSRP.10.03.2020.p9906

www.ijsrp.org 
induction. Group I received inj. Propofol $2 \mathrm{mg} / \mathrm{kg}$ iv and group II etomidate $0.3 \mathrm{mg} / \mathrm{kg}$ iv.All study drugs were prepared by an anaesthesiologist who was blinded to the details of the study. Volume of medication and speed of injection were equal in all three groups. After induction of anesthesia, hemodynamic variables were recorded. Inj rocoronium1-2mg/mg given. Laryngoscopy and endotracheal intubation was done by experienced anesthesiologist. Duration of laryngoscopy was kept less than 10 seconds. Trachea was intubated with adequate size of endotracheal tube. Proper placement of ETT was confirmed by capnography and bilateral auscultation of chest. Following successful placement of ET tube anesthesia was maintained by isoflurane 1-1.5\% and equal mixture of oxygen-nitrous oxide $(4 \mathrm{~L} / \mathrm{min}$ ) along with intermittent bolus of rocuronium as required throughout the surgery.

Heart rate, systolic blood pressure, diastolic blood pressure ,mean arterial blood pressure and oxygen saturation were continuously monitored and recorded before induction and after induction at 1 minute , 2 minute, 5 minutes ,10 minutes, 20 minutes,30 minutes,60 minute by the anaesthesiologist who is blinded to the study .

\section{OBSERVATIONS AND RESULTS}

This prospective randomized double blind study was carried out on 60 patients between the age group 18-60 years at MIMS, Rajasthan Jaipur to evaluate the hemodynamic effects of etomidate and propofol as induction agent in elective surgeries.

\section{Age distribution of patients in different groups (Table 1)}

\begin{tabular}{|c|c|c|c|c|c|c|c|}
\hline \multirow[t]{2}{*}{ Age(in years) } & \multirow[t]{2}{*}{$\mathrm{N}$} & \multicolumn{2}{|c|}{$\begin{array}{c}\text { Group I } \\
(\mathrm{n}-30)\end{array}$} & \multicolumn{2}{|c|}{$\begin{array}{c}\text { Group II } \\
(\mathrm{n}-30)\end{array}$} & \multirow[t]{2}{*}{$x^{2}$} & \multirow[t]{2}{*}{ p-value } \\
\hline & & $\mathrm{F}$ & $\%$ & $\mathrm{~F}$ & $\%$ & & \\
\hline $18-30$ & 10 & 33.33 & 8 & 26.66 & 8 & \multirow[t]{4}{*}{11.45} & \multirow[t]{4}{*}{0.009} \\
\hline $31-40$ & 12 & 40 & 4 & 13.33 & 4 & & \\
\hline $41-50$ & 5 & 16.66 & 4 & 13.33 & 4 & & \\
\hline $51-60$ & 3 & 10 & 14 & 46.66 & 14 & & \\
\hline
\end{tabular}

As evident from the table age of the patients was comparable both the groups.(p=0.990). The minimum numbers of patients were in the age group of $41-50$ years. 


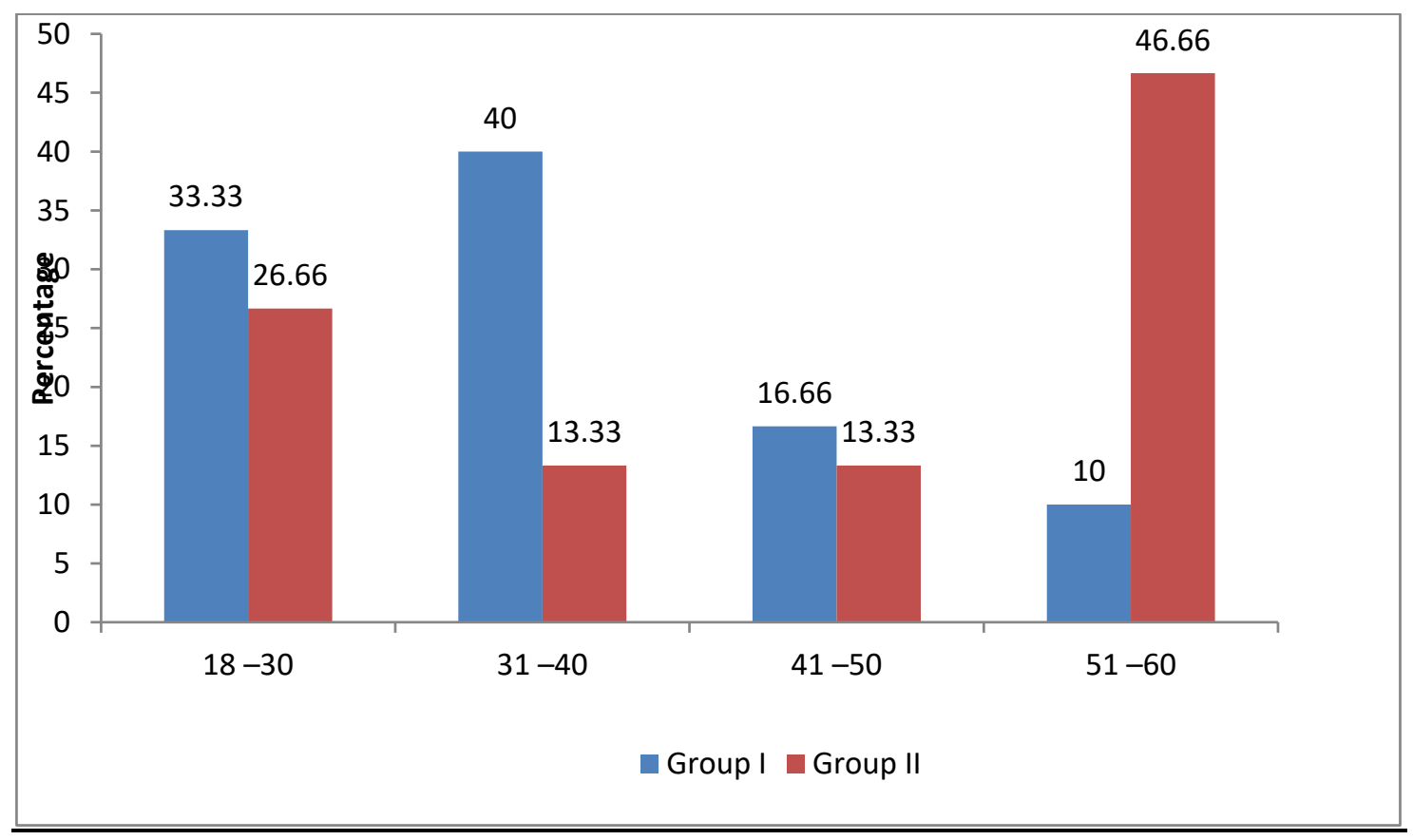

Distribution of patients in different groups according to gender (Table 2)

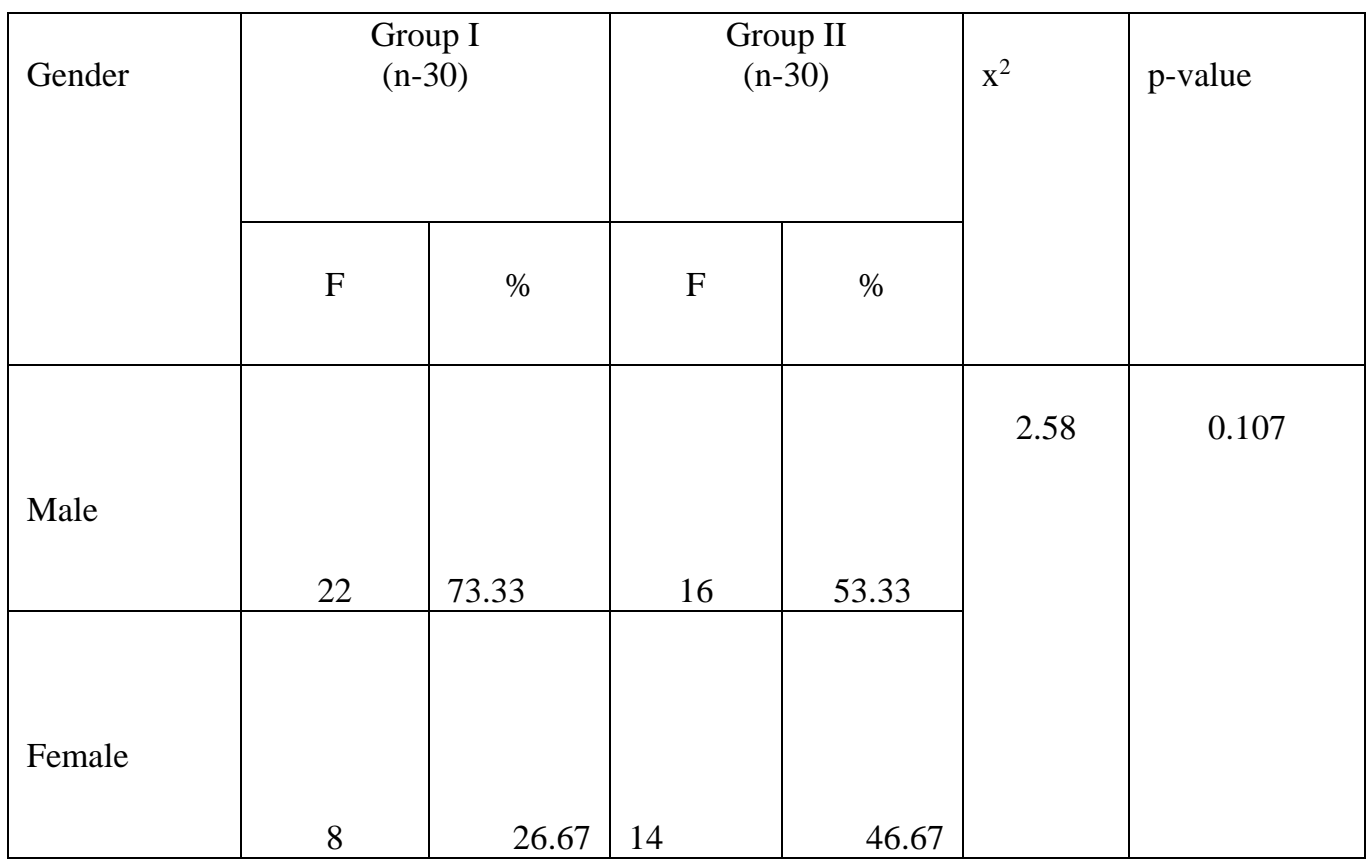

As evident from the table there were 38 males and 22 females in our study. Gender comparison was comparable among both groups. $(\mathrm{p}=0.107)$ 


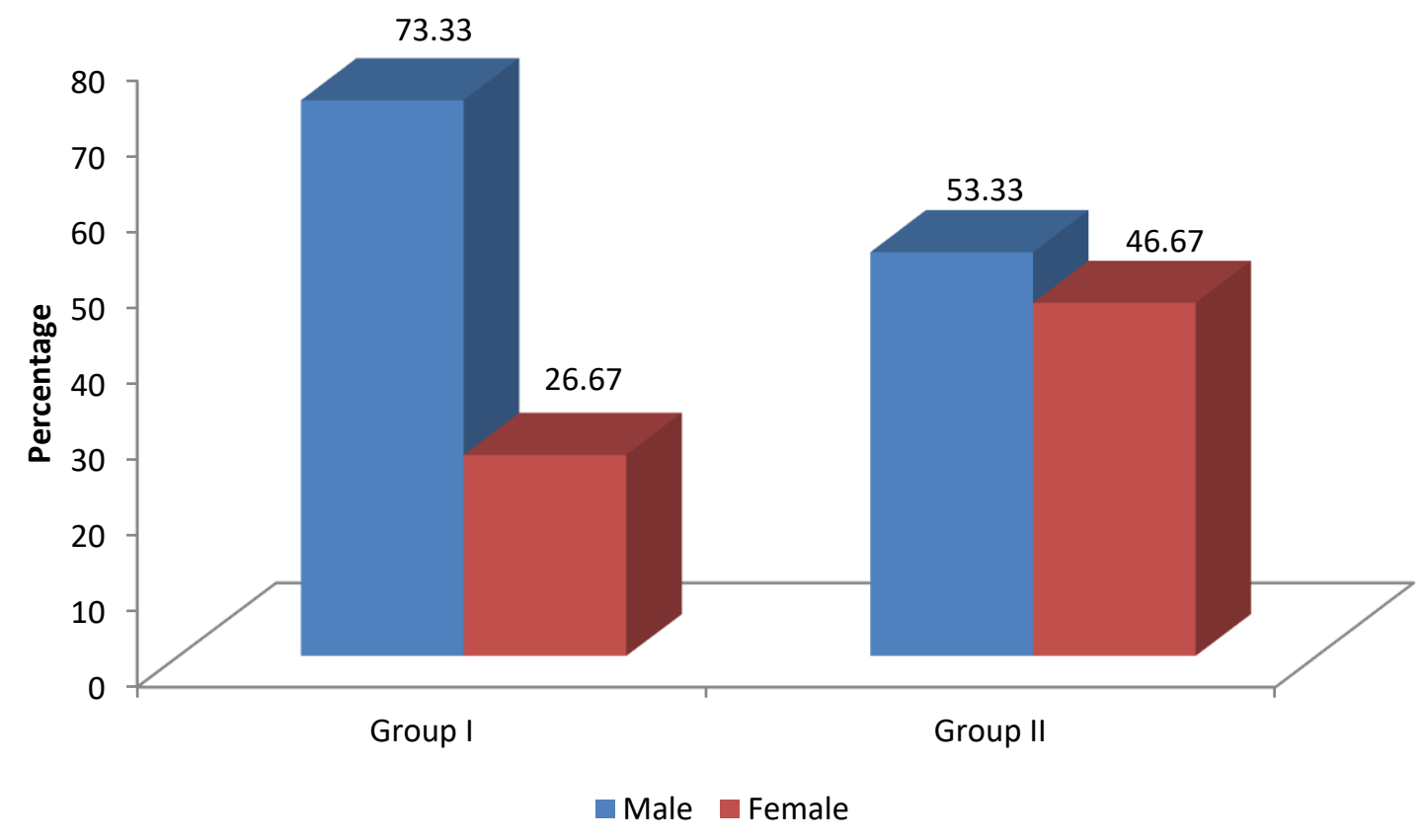

Mean distribution of weight in different groups (Table 3)

As evident from

\begin{tabular}{|l|l|c|c|}
\hline & $\begin{array}{l}\text { Weight(in Kg) } \\
\text { Mean } \pm \text { SD }\end{array}$ & F & P-value \\
\hline Group I (n-30) & $58.06 \pm 1.76$ & \multirow{2}{*}{0.241} & 0.308 \\
\hline Group II (n -30) & $57.61 \pm 1.61$ & & \\
& & & \\
\hline
\end{tabular}

weight $(\mathrm{kg})$ in group I was $58.06 \pm 1.76$, in group II was $57.61 \pm 1.61$ which was statistically non significant. $(\mathrm{p}=0.308$ 


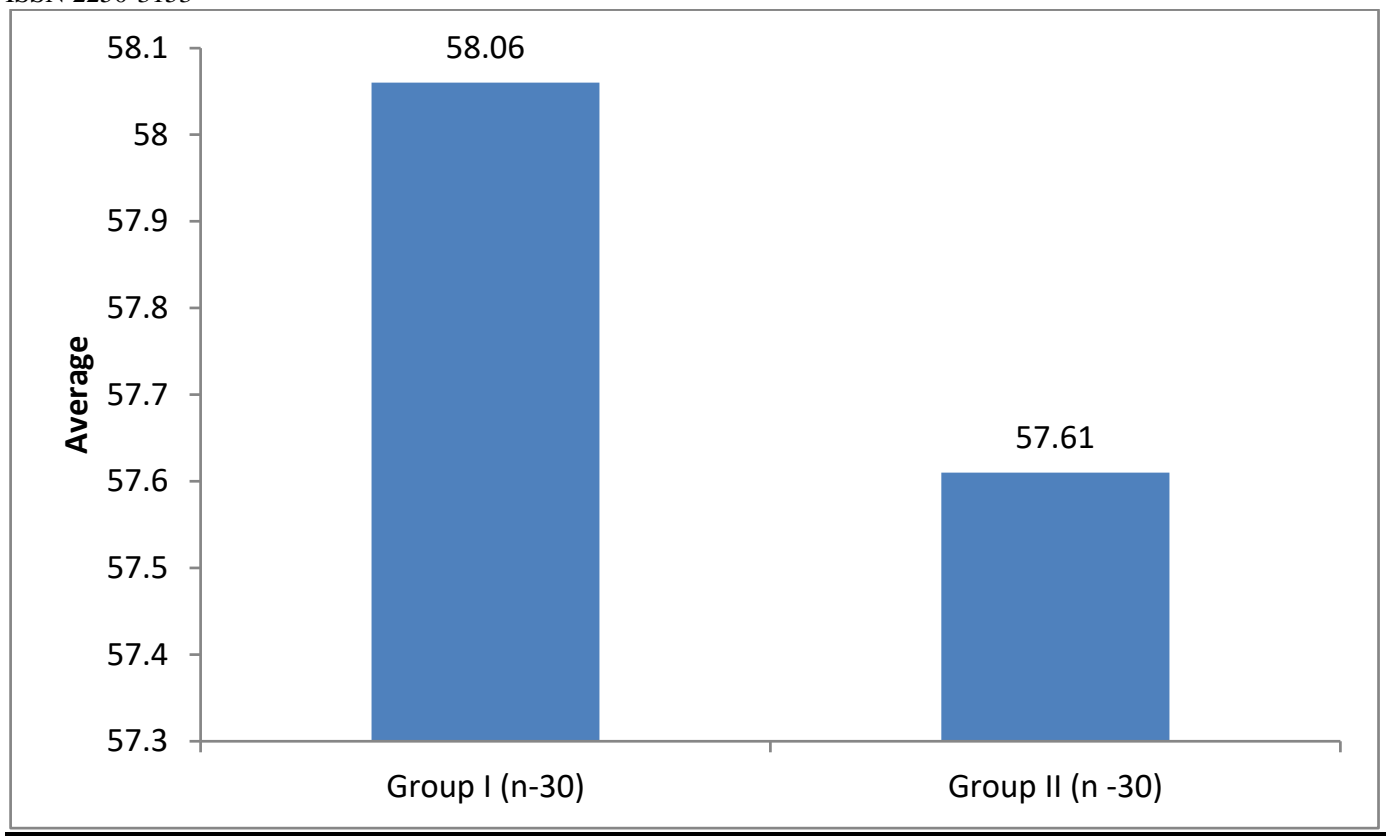

HEART RATE (Table 5.1)

\begin{tabular}{|c|c|c|c|c|}
\hline Time & $\begin{array}{c}\text { Group } \\
\text { I } \\
(\mathrm{n}-30)\end{array}$ & $\begin{array}{c}\text { Group } \\
\text { II } \\
(\mathrm{n}-30)\end{array}$ & F & p-value \\
\hline Baseline & $81.53 \pm 12.29$ & $84.53 \pm 9.81$ & 2.79 & 0.300 \\
\hline At 0 minute & $73.03 \pm 11.37$ & $76.73 \pm 8.33$ & 4.32 & 0.156 \\
\hline At 1 minute & $69.03 \pm 10.65$ & $74.83 \pm 8.65$ & 2.68 & 0.024 \\
\hline At 2 minute & $79 \pm 8.53$ & $80.76 \pm 10.22$ & 0.000 & 0.471 \\
\hline At 5 minute & $75.90 \pm 8.26$ & $79.13 \pm 9.19$ & 0.185 & 0.157 \\
\hline At 10 minute & $74.86 \pm 9.11$ & $78.60 \pm 8.70$ & 0.572 & 0.110 \\
\hline At 30 minute & $73.43 \pm 9.79$ & $78.53 \pm 10.14$ & 0.266 & 0.052 \\
\hline At 60 minute & $74.23 \pm 9.52$ & $79.06 \pm 10.05$ & 0.000 & 0.061 \\
\hline
\end{tabular}

As evident from the table the baseline heart rate was comparable among the groups. Mean HR in Group I was $81.53 \pm 12.29$,in group II was $84.53 \pm 9$..The $\mathrm{F}$ value was 2.792 and $\mathrm{p}$ value was 0.300 .Statistically significant fall in heart rate was seen at 1 minute of induction $(\mathrm{p}<0.05)$

\section{Systolic blood pressure (SBP) (Table 6.1)}




\begin{tabular}{|c|c|c|c|c|}
\hline Time & $\begin{array}{c}\text { Group } \\
\text { I } \\
(\mathrm{n}-30)\end{array}$ & $\begin{array}{c}\text { Group } \\
\text { II } \\
(\mathrm{n}-30)\end{array}$ & F & p-value \\
\hline Baseline & $139.16 \pm 9.39$ & $135.13 \pm 8.71$ & 1.07 & 0.090 \\
\hline At 0 minute & $101.86 \pm 7.94$ & $118.56 \pm 14.44$ & 18.10 & 0.000 \\
\hline At 1 minute & $94.10 \pm 9.38$ & $112.93 \pm 17.06$ & 14.30 & 0.000 \\
\hline At 2 minute & $94.76 \pm 7.37$ & $127.26 \pm 10.97$ & 3.44 & 0.000 \\
\hline At 5 minute & $96.40 \pm 8.70$ & $125.60 \pm 9.34$ & 0.60 & 0.000 \\
\hline At 10 minute & $97.33 \pm 6.37$ & $120.26 \pm 13.42$ & 9.35 & 0.000 \\
\hline At 30 minute & $99.13 \pm 6.53$ & $125.23 \pm 7.84$ & 0.21 & 0.000 \\
\hline At 60 minute & $99.76 \pm 5.65$ & $125.30 \pm 8.01$ & 1.36 & 0.000 \\
\hline
\end{tabular}

As evident from the table base line SBP was comparable among the groups. Mean SBP in Group I was $139.16 \pm 9.39$, in group II was 135.13 \pm 8.71 . The F value was 1.07 and $\mathrm{p}$ value was 0.090 . Statistically significant fall in SBP was observed in group I at 0min which persisted till 60 minutes.

Diastolic blood pressure (Table 7.1)

\begin{tabular}{|c|c|c|c|c|}
\hline Time & $\begin{array}{c}\text { Group } \\
\text { I } \\
(\mathrm{n}-30)\end{array}$ & $\begin{array}{c}\text { Group } \\
\text { II } \\
(\mathrm{n}-30)\end{array}$ & F & p-value \\
\hline Baseline & $87.43 \pm 4.04$ & $86.40 \pm 4.53$ & 0.799 & 0.355 \\
\hline At 0 minute & $58.06 \pm 6.17$ & $74.66 \pm 10.63$ & 7.74 & 0.000 \\
\hline At 1 minute & $56.23 \pm 5.70$ & $69.73 \pm 11.97$ & 13.73 & 0.000 \\
\hline At 2 minute & $57.86 \pm 5.37$ & $80.36 \pm 7.55$ & 3.37 & 0.000 \\
\hline At 5 minute & $58.56 \pm 7.69$ & $80.20 \pm 6.25$ & 0.06 & 0.000 \\
\hline At 10 minute & $56.93 \pm 5.81$ & $79.63 \pm 6.17$ & 0.80 & 0.000 \\
\hline At 30 minute & $61.30 \pm 9.21$ & $80.43 \pm 5.82$ & 1.95 & 0.000 \\
\hline At 60 minute & $58.23 \pm 6.32$ & $80.56 \pm 7.33$ & 4.97 & 0.000 \\
\hline
\end{tabular}


As evident from the table base line DBP was comparable among the groups .Mean DBP in Group I was 87.43 \pm 4.04 , in group II was $86.40 \pm 4.53$. The $\mathrm{F}$ value was 0.799 and $\mathrm{p}$ value was 0.355 . Statistically significant fall in DBP was observed throughout the procedure

Mean blood pressure (Table 8.1)

\begin{tabular}{|c|c|c|c|c|}
\hline Time & $\begin{array}{c}\text { Group } \\
\text { I } \\
(\mathrm{n}-30)\end{array}$ & $\begin{array}{c}\text { Group } \\
\text { II } \\
(\mathrm{n}-30)\end{array}$ & F & p-value \\
\hline Baseline & $104.33 \pm 3.86$ & $98.83 \pm 17.24$ & 2.64 & 0.094 \\
\hline At 0 minute & $72.36 \pm 6.39$ & $88.63 \pm 11.76$ & 15.36 & 0.000 \\
\hline At 1 minute & $68.36 \pm 6.29$ & $84.20 \pm 13.40$ & 18.92 & 0.000 \\
\hline At 2 minute & $70.60 \pm 7.10$ & $95.96 \pm 8.22$ & 2.30 & 0.000 \\
\hline At 5 minute & $70.83 \pm 8.14$ & $95.03 \pm 6.78$ & 0.01 & 0.000 \\
\hline At 10 minute & $70.13 \pm 6.03$ & $94.53 \pm 5.70$ & 0.35 & 0.000 \\
\hline At 30 minute & $70.46 \pm 4.56$ & $95.73 \pm 5.86$ & 0.31 & 0.000 \\
\hline At 60 minute & $72.26 \pm 6.18$ & $95.33 \pm 5.76$ & 0.98 & 0.000 \\
\hline
\end{tabular}

As evident from the table base line MBP was comparable among the groups .Mean MBP in Group I was104.33 \pm 3.86 , in group II was $98.83 \pm 17.24$. The F value was 2.64 and $\mathrm{p}$ value was 0.094 . Statistically significant fall in MBP was observed at 0min which persisted till 60 minutes. 
$\underline{\mathrm{SpO}_{2}}$ (Table 9.1)

\begin{tabular}{|c|c|c|c|c|}
\hline Time & $\begin{array}{c}\text { Group } \\
\text { I } \\
(\mathrm{n}-30)\end{array}$ & $\begin{array}{c}\text { Group } \\
\text { II } \\
(\mathrm{n}-30)\end{array}$ & F & p-value \\
\hline Baseline & $99.10 \pm 0.80$ & $99.13 \pm 0.86$ & 0.76 & 0.877 \\
\hline At 0 minute & $99.10 \pm 0.80$ & $98.83 \pm 2.03$ & 1.47 & 0.507 \\
\hline At 1 minute & $96.10 \pm 16.28$ & $99.13 \pm 0.86$ & 3.30 & 0.312 \\
\hline At 2 minute & $99.10 \pm 0.80$ & $99.13 \pm 0.86$ & 0.07 & 0.877 \\
\hline At 5 minute & $96.10 \pm 16.47$ & $99.23 \pm 0.77$ & 3.35 & 0.302 \\
\hline At 10 minute & $99.13 \pm 0.81$ & $99.16 \pm 0.74$ & 0.58 & 0.870 \\
\hline At 30 minute & $96.16 \pm 16.48$ & $98.93 \pm 0.82$ & 3.40 & 0.362 \\
\hline At 60 minute & $99 \pm 0.78$ & $99.36 \pm 0.71$ & 0.09 & 0.065 \\
\hline
\end{tabular}

No significant change was seen in SPO2 among both the groups at various time intervals $(\mathrm{p}>0.05)$

$\underline{\text { ETCO2 }}$ (Table 10.1)

\begin{tabular}{|c|c|c|c|c|}
\hline Time & $\begin{array}{c}\text { Group } \\
\text { I } \\
(\mathrm{n}-30)\end{array}$ & $\begin{array}{c}\text { Group } \\
\text { II } \\
(\mathrm{n}-30)\end{array}$ & F & p-value \\
\hline Baseline & $37.23 \pm 3.09$ & $38.23 \pm 3.96$ & 2.19 & 0.280 \\
\hline At 0 minute & $34.83 \pm 1.17$ & $34.83 \pm 1.20$ & 0.08 & 1.000 \\
\hline At 1 minute & $36.73 \pm 0.84$ & $38.16 \pm 6.63$ & 1.82 & 0.246 \\
\hline At 2 minute & $34.56 \pm 1.07$ & $34.80 \pm 1.06$ & 0.02 & 0.401 \\
\hline At 5 minute & $34.23 \pm 1.65$ & $34.73 \pm 1.28$ & 3.34 & 0.196 \\
\hline At 10 minute & $36 \pm 1.48$ & $32.93 \pm 1.96$ & 0.28 & 0.000 \\
\hline At 30 minute & $32.96 \pm 0.76$ & $33.20 \pm 0.80$ & 0.99 & 0.255 \\
\hline
\end{tabular}


Base line ETCO2 was comparable at 0 min among both the groups. Statistically significant rise was seen at 1 min which persisted up to 60 minutes. $(\mathrm{p}<0.05)$

\section{DISCUSSION}

General anesthetic induction agents may decrease arterial blood pressure via cardio vascular depression and attenuation of autonomic nervous system activity. On the other hand laryngoscopy and endotracheal intubation elicit vasopressor responses such as hypertension and tachycardia. Various attempts have been made to overcome and attenuate hemodynamic instability during induction, laryngoscopy, and intubation. in many studies induction agents, either alone or in combination have been used to achieve minimum cardiovascular. Although many studies used thiopentol sodium as sole induction agent, it was found unsatisfactory as it does not suppress airway reflexes. Propofol has been advocated as a preferred i.v induction agent but induction with propofol alone causes remarkable reduction in blood pressure. Various studies shows that etomidate provide better hemodynamic profile but for its adverse effect like myoclonus and adrenal suppression. Recently Hacettepe University, studied propofol and etomidate for availability of admixture and reported that etofol (admixture of etomidate and propofol) can be used for induction agent.

After approval from institutional ethical committee we conducted a randomized double blind study in the department of anesthesia NIMS during the period of 20-02-2018 to 10-04-2018, compressing 60 patients of ASA grade I and II , age between 18-60 who were randomly selected and divided into two groups 30 each.

Informed consent were taken from all the patients were induced in Group I Induction with Propofol $2 \mathrm{mg} / \mathrm{kg}$, Group II induction with etomidate $0.3 \mathrm{mg} / \mathrm{kg}$ and the patient was intubated and maintain on oxygen and nitrous (50-50\%), isofluraine

Hemodynamic parameters and adverse effects if any were noted at various time intervals. The data obtained from this study was organised and analysed statictiaclly. Observation was made and results were drawn.

\section{Demographic profile}

In our study out of total (60) number of male patients was 38 and female patients were 22. No significant difference ( $\mathrm{p}=0.107$ and $\mathrm{X}^{2}=2.58$ ) was observed in gender distribution between the groups (table 2).

Demographic profile of the study done by $\mathbf{K}$ Meena et al also had comparable age group $(\mathrm{p}=0.178)$ and comparable gender distribution $(\mathrm{p}=0.241) .7$

\section{Heart rate (HR)}

In our study baseline heart rate was comparable among the groups. Mean HR in Group I was $81.53 \pm 1.76$, in group II was $84.5 \pm 9.8$. The $\mathrm{F}$ value was 2.792 and $\mathrm{p}$ value was 0.300 .Statistically significant fall in heart rate was seen at 1 minute of induction $(\mathrm{p}<0.05)$ (table 5.1)

Masoudifar M et al concluded there were no significant difference among groups I (Propofol) and II (Etomidate) in terms of $\mathrm{HR}(\mathrm{P}=$ 0.47). ${ }^{(8)}$

Singh $\mathbf{R}$ et al studied there was a significant increase from baseline in heart rate $(\mathrm{P}=0.001)$ at 1 minute after intubation. This statistically significant difference can be due to ASA grade III patients with coronary artery disease and left ventricular dysfunction. ${ }^{(9)}$ Mulier JP et al studied cardiovascular effects of propofol in comparison with thiopental and observed no statistically significant difference in heart rate and cardiac index. ${ }^{(10)}$ 


\section{SYSTOLIC BLOOD PRESSURE}

In our study base line SBP was comparable both the groups. Mean SBP in Group I was139.16 \pm 9.39, in group II was $135.13 \pm$ 871.The $\mathrm{F}$ value was 1.07 and $\mathrm{p}$ value was 0.090. Statistically significant fall in SBP was observed in group I at 0min which persisted till 60mintues (table 6.1).

Findings of our study are comparable with the studies of MasoudifarM et $\mathbf{a l}^{8}$, Geeta Karki et al ${ }^{11}$, Kalogridaki M et al ${ }^{12}$ and Meena et al ${ }^{7}$.

Masoudifar M et al concluded that changes of SBP in the group B (Propofol) was statistically significantly $(\mathrm{P}=0.019$ ), clinically significant hypotension was seen in $26.1 \%$ of patients in group B (Propofol) and $8 \%$ of patients in group A (Etomidate). Patients of group A (Etomidate) had more stable hemodynamic parameters. ${ }^{(8)}$

Geeta Karki et al concluded that Etomidate offers superior hemodynamic stability during induction compared to thiopentone and propofol, similar to our study. ${ }^{(9)}$

Kalogridaki M et al found statistically significant drop in systolic blood pressure in group P (Propofol) when compared with the baseline value (mean decrease $15.2 \mathrm{mmHg}, 95 \%$ CI 5.6-24.8 mmHg, $\mathrm{p}=0.001$ ). ${ }^{(10)}$

Meena et al observed significant fall in systolic blood pressure in group I (Propofol) as compared to group II (etomidate) Systolic blood pressure prior to induction was non significant $(\mathrm{p}=0.536)$. There was significant fall in blood pressure in group I at induction which persisted till 5 minutes after intubation $(\mathrm{p}=0.000)$. The combination of etomidate plus propofol had better hemodynamic stability than etomidate or propofol alone. ${ }^{(7)}$

\section{DIASTOLIC BLOOD PRESSURE}

In our study base line DBP was comparable among the groups. Mean DBP in Group I was $87.43 \pm 4.04$,in group II was 86.40 \pm 4.53 . The F value was 7.99 and $p$ value was 0.355. Statistically significant fall in DBP was observed throughout the procedure (table 7.1).

MasoudifarM et al found that changes of the DBP was significantly higher in the group $\mathrm{B}$ (Propofol) $(\mathrm{P}=0.001)$ at various time intervals, which is comparable with our study ${ }^{(8)}$

\section{MEAN BLOOD PRESSURE}

In our study base line MBP was comparable among the groups. Mean MBP in Group I was104.3 \pm 3.86 , in group II was $98.83 \pm$ 17.24. The F value was 2.64 and $\mathrm{p}$ value was 0.94 . Statistically significant fall in MBP was observed at 0min which persisted till 60 minutes.(table 8.1)

MasoudifarM et al found that changes in MBP was statistically significant in group B ( $\mathrm{P}=0.008)$. Hypotension happened in $26.1 \%$ of group B and $8 \%$ of group A ( $\mathrm{P}=0.09) .{ }^{(8)}$

Moller et al used propofol and etomidate in general anesthesia induction and found that MBP values after induction in the propofol group were significantly lower than those of the other group. Following intubation, the MBP values in the etomidate group were statistically significantly higher than those of the propofol groups. ${ }^{(13)}$

\section{SPO2}

In our study no significant change was seen in SPO2 in both groups ( $\mathrm{p}$ value >0.05). (Table 9.1)

\section{ETCO2}


In our study ETCO2 varies from minimum $30 \mathrm{mmHg}$ to $45 \mathrm{mmHg}$ maximum. This is statistically significant at various time intervals but changes in ETCO2 are not clinically significant and therefore no clinical intervention was required. (Table 10.1)

\section{References}

1. Thomas J. Ebert, Michael Muzi et al. sympathetic response to induction of anesthesia in humans with propofol and etomidate Anesthesiology 5 1992, Vol.76 (5); 725-733.

2. King BD, Harris LC, Griefenstein FE et al. Reflex cardiovascular response to direct lyrngoscopy and intubation performed during anesthesia .Anaesthesiology 1951;13:556-66.

3. Wyckoff CC Endotracheal intubation effects on blood pressure and heart rate. Anaesthesiology 1960; 21: 153-8.

4. Burnstien CL, Pinto Lo FJ and Newman W. Electrocardiograph studies during tracheal intubation: effect during routine techniques. Anaesthesiology 1950; 11: 224-5.

5. Hassan HG, Sharkawry EL and foud A. Hemodynamic and catecholamine response to laryngoscopy with or without endotracheal intubation. ActaAnaesth Scand 1990; 35: 442-7.

6. Russel WJ, Morris RG, Frewin D B et al. Changes in plasma catecholamine concentrations during endotracheal intubation. Br J Anaesth 1981; 53: 837-9.

7. Meena K, Meena R, Nayak SS, Prakash S, Kumar A (2016) A Comparative Study of Effect of Propofol, Etomidate and Propofol Plus Etomidate Induction on Hemodynamic Response to Endotracheal Intubation: A RCT. J AnesthClin Res 7:622. doi: $10.4172 / 2155-6148.1000622$.

8. Masoudifar M1, Beheshtian E2.Comparison of cardiovascular response to laryngoscopy and tracheal intubation after induction of anesthesia by Propofol and Etomidate Res Med Sci.2013; 18(10):870-4.

9. Singh R, Choudhury M, Kapoor PM, Kiran U. A randomized trial of anesthetic induction agents in patients with coronary artery disease and left ventricular dysfunction. Ann Card Anaesth. 2010; 13:217-23

10.Mulier JP, Patric F, Aken HV, Vermant G; Cardiodynamic Effects of Propofol In Comparison With Thiopental; Assessment with A TEE Approach. AnaesthAnalg. 1991; 72:28-35.

11. GeetaKarki, Vishwadeep Singh, AbhishekBarnwal, Lalit Singh.“A Comparative Evaluation of Hemodynamic Characteristics of the Three Induction Agents - Etomidate, Thiopentone and Propofol”. Journal of Evolution of Medical and Dental Sciences 2014; Vol. 3, Issue 34, August 11; Page: 9133-9141, DOI: 10.14260/jemds/2014/3179, 41

12. Kalogridaki M, Souvatzis X, Mavrakis HE, Kanoupakis EM, Panteli A, et al. (2011) Anaesthesia for cardioversion: a prospective randomised comparison of propofol and etomidate combined with fentanyl.Hellenic J Cardiol 52: 483-488.

13. Moller Petrun A1, Kamenik M. Bispectral index-guided induction of general anaesthesia in patients undergoing major abdominal surgery usingpropofol or etomidate: a double-blind, randomized, clinical trial.Br J Anaesth.2013; 110(3):388-96. 